\title{
LA CRISIS DE LOS SACERDOTES Y RELIGIOSOS (1965-1972): REFLEJO Y FACTOR DEL PROCESO DE SECULARIZACIÓN EN ESPAÑA*
}

\author{
POR \\ RAFAEL RUIZ ANDRÉS ${ }^{1}$ \\ Instituto de Ciencias de las Religiones de la Universidad Complutense de Madrid
}

\begin{abstract}
RESUMEN
El artículo aborda un capítulo importante para la comprensión de la aceleración del proceso de secularización en España (1965-1972): la crisis de la vida clerical y religiosa. En un contexto de profundo cambio cultural y socioeconómico, el clero y los religiosos experimentaron de manera destacada las contradicciones que se abrían entre una sociedad en transformación y la herencia religiosa recibida, traduciendo al lenguaje eclesial parte de los dilemas de la época. Para el estudio de esta temática, el artículo propone una revisión sociohistórica del proceso de secularización, realizada a partir del análisis de documentación archivística, hemerotecas, estadísticas y entrevistas sobre la crisis clerical y religiosa. La información aportada por las fuentes nos conduce, como conclusión, a la confirmación de que la crisis de este sector en la España posconciliar fue reflejo y factor a un mismo tiempo de la profunda transformación religiosa que la sociedad española estaba viviendo en paralelo.
\end{abstract}

PALABRAS CLAVE: Historia Contemporánea; sociología histórica; secularización; iglesia católica; sacerdotes y religiosos; España; Concilio Vaticano II.

\section{THE CLERICAL AND RELIGIOUS CRISIS (1965-1972): A REFLECTION AND A FACTOR OF THE SECULARISATION PROCESS IN SPAIN}

\begin{abstract}
The article deals with an important chapter for the understanding of the acceleration of the secularisation process in Spain (1965-1972): the crisis of clerical and religious life. In a context of profound cultural and socio-economic change, this sector experienced in a remarkable way the contradictions that opened up between a society in transformation and the religious heritage and, in parallel, they translated part of the dilemmas of the moment into ecclesial language. In order to study this topic, the article carries out a socio-historical review of the process of secularisation based on the analysis of archival documentation, newspaper libraries, statistics and interviews. The information provided by the sources leads us, as a conclusion, to the confirmation that the crisis of this sector in post-conciliar Spain was both a reflection and a factor of the deep religious transformation that Spanish society was undergoing at the same time.
\end{abstract}

KEY WORDS: Contemporary History; historical sociology; secularisation; Catholic Church; priesthood and religious orders; Spain; Vatican Council II.

Cómo CITAR ESTE ARTículo / CITATION: Ruiz Andrés, Rafael. 2021. «La crisis de los sacerdotes y religiosos (1965-1972): reflejo y factor del proceso de secularización en España». Hispania Sacra LXXIII, 147: 259-271. https://doi.org/10.3989/hs.2021.022

Recibido/Received 25-09-2019

Aceptado/Accepted $\quad 17-01-2020$

* El autor, ha sido beneficiario de un contrato FPU-MEC (Ministerio de Educación y Ciencia), con referencia FPU14/05460. El presente artículo se ha realizado dentro del periodo de esta ayuda. Este trabajo ha sido posible gracias al apoyo del proyecto de investigación: «Modernidad y religión en la España del siglo XX: entre el consenso y la ruptura» (PGC2018-099909-B-I00), cuyo Investigador Principal (IP) es Julio de la Cueva Merino.

rafaru01@ucm.es / ORCID iD: https://orcid.org/0000-0002-9667-3052 
CLÉRIGOS Y RELIGIOSOS EN CRISIS: ¿UN FACTOR CATÓLICO DE LA SECULARIZACIÓN? ${ }^{2}$

Reflexionar sobre el sector de los sacerdotes y religiosos, y la secularización nos conduce a pensar en dos mundos distintos, en los polos de un binomio diferencial. De un lado, los responsables de la gestión y transmisión de lo sagrado, punto nodal de conexión entre la sacramentalidad, la educación y la asistencia católica con el resto de la población. Por otro, un proceso que, desde los albores de su construcción moderna, ha sido descrito como una continuada mundanización que acaba por penetrar en los muros de los monasterios e iglesias. Así también lo denunciaba más recientemente el pontífice Juan Pablo II (1982) por medio de su oración para que los presbíteros no entristeciesen al Espíritu con el «secularismo» o con la conformidad "a este siglo». ${ }^{3}$

Sin embargo, una mirada histórica más detenida al proceso de secularización, y concretamente a las profundas transformaciones sociorreligiosas acontecidas en la España de la segunda mitad del siglo XX, nos adentra en un una realidad más ambigua y difusa. Frente al binomio imaginado, emergen las confluencias que se efectuaron en ciertos momentos históricos entre los cambios en este fundamental sector de la Iglesia católica, el clero y los religiosos, y la acentuación del propio proceso de secularización. $\mathrm{Y}$, más específicamente, en un momento tan crítico como fue el denominado posconcilio, en el que el cierre del Concilio Vaticano II coincidió con la aceleración del proceso de secularización en países como España (Pérez-Agote 2012), contexto geográfico en el que se ubica el presente artículo.

La hipótesis principal de este texto emerge de la idea de que la aceleración de los cambios sociorreligiosos a partir de los años sesenta tuvo en los dilemas vividos en la Iglesia no solo una consecuencia fundamental, sino también una causa importante. De este modo, la crisis profunda que se experimentó en el clero y los religiosos actuó como reflejo y factor del propio proceso de transformación sociorreligiosa.

La crisis del clero y de los religiosos sintetizó parte de las problemáticas de un contexto en profunda transformación sociocultural, a la par que aumentaba el radio de expansión de los distintos dilemas experimentados a otros sectores poblacionales por medio de su presencia en la estructura social y su labor pastoral y educativa. Además, la asunción por parte de los gestores y transmisores de la religiosidad de los cuestionamientos del momento contribuyó igualmente a que la transformación socioeconómica y demográfica que se estaba experimentando se tradujese en una crisis simbólica: la erosión de aquella religiosidad de parroquias y sacramentos, de misiones y tiempos fuertes, en la que los cambios vividos por el propio clero concentraban la crisis de todo un universo simbólico.

2 Abreviaturas utilizadas. AESI-A=Archivo de la Compañía de Jesús en España; $A G A=A r c h i v o$ General de la Administración; CONFER=Conferencia Española de Religiosos; DIS=Departamento de Investigación Sociológica; FAB=Fondo Álvarez Bolado; FGC=Fondo Gómez Caffarena; FGE=Fondo Gabinete de Enlace; FOESSA=Fomento de Estudios Estadísticos y Sociología Aplicada; ISPA=Instituto de Sociología y Pastoral Aplicadas.

3 Juan Pablo II. 1982. Carta del Santo Padre Juan Pablo II a los Sacerdotes con ocasión del Jueves Santo 1982. https://w2.vatican. va/content/john-paul-ii/es/letters/1982/documents/hf_jp-ii_ let_19820325_s acerdoti-giovedisanto.html.
A partir de la hipótesis presentada, el artículo analiza en profundidad la confluencia entre la crisis del sector religioso y clerical y el inicio de la denominada por el sociólogo Pérez-Agote (2012) como «segunda oleada de secularización». Más concretamente, la cronología a través de la cual abordaremos esta interrelación se encuadra entre 1965 y los primeros años setenta, entre el cierre del Concilio Vaticano II y los debates abiertos tras el fin de la Asamblea Conjunta Obispos Sacerdotes (1971), dos acontecimientos que marcaron la primera etapa del debate posconciliar en España y que custodian el periodo en el que exploraremos la hipótesis de la crisis del clero como causa y consecuencia de la aceleración del proceso de secularización.

El presente estudio desea contribuir, además, al mayor conocimiento de las transformaciones sociorreligiosas en España a partir de los cambios en un sector particular pero de indudable importancia para la comprensión de las dinámicas sociales del momento; importancia que contrasta con la insuficiente atención que ha sido concedida al tema. La crisis del clero que aconteció en los años sesenta ha sido más analizada pastoral y teológicamente (González de Cardedal 1967, 2010) que historiográfica y sociológicamente, lo que establece un contrapunto con el derrotero académico de contextos como el francés, en el que se ha profundizado en la revolution silencieuse que implicó la metamorfosis del clero (Béraud 2007) o en la conexión entre las cuestiones teológicas y sociológicas del proceso de secularización (Cuchet 2018). En el caso español, mientras que en los trabajos históricos han primado los análisis relacionados con realidades específicas del clero durante este periodo (i.e. el caso de los curas obreros, en Berzal de la Rosa 2007; Centeno, Díez y Pérez 2009) o las imprescindibles, pero más amplias, tensiones y disputas en el seno de la Iglesia posconciliar (Montero 2009; Raguer 2006; Martín de Santa Olalla y Serrano 2016), los análisis sociológicos han abordado la crisis del sector religioso y clerical más como un dato añadido a la descripción del contexto social que como un caso de estudio per se. La investigación realizada por Jesús Domínguez (2001), que incorpora una valiosa y amplia información estadística sobre las transformaciones en este sector, constituye una notable excepción.

Este artículo opta por una aproximación sociohistórica al tema propuesto, que coincide con el actual reclamo académico del estudio de la secularización a partir de casos específicos, y no desde la abstracción metahistórica de los conceptos (Gorski 2003). Esta perspectiva se encuentra fundamentada en el acopio de materiales sobre los que se sustenta la investigación: el análisis de los múltiples informes que en este periodo se realizaron sobre la crisis del clero, ${ }^{4}$ hemerotecas, fuentes archivísticas y la incorporación de dis-

4 Para conocer la situación del clero entre 1969 y 1970 resulta fundamental la Encuesta-consulta al clero de España, dirigida por la Comisión Episcopal del Clero y realizada por el DIS de Fomento Social. Respondieron 59 de las 64 diócesis españolas, alcanzando una muestra de 15.449 sacerdotes (el $85 \%$ del clero secular español del momento). Junto con las cifras ofrecidas de esta encuesta en la publicación de la propia Asamblea Conjunta (1971), tomaré los datos recogidos en la Guía de la Iglesia en España de 1973 (Oficina General 1973). También es interesante e ilustrativa la encuesta realizada entre los seminaristas españoles del curso 1968-1969, efectuada en cuarenta y seis seminarios de los setenta entonces existentes. Citaré dos fuentes de procedencia de los datos relativos a los seminaristas: un artículo de 
tintos testimonios que se han recopilado a partir de un estudio cualitativo de "historias de vida»/historia oral realizado por el autor.

Exploraré, a continuación, las confluencias entre la transformación sociorreligiosa de finales de los sesenta y la crisis del clero, apuntadas en estas premisas de partida, en tres puntos:

- En primer lugar, analizaremos la expansión de la profunda transformación social que se experimentó en los años sesenta y su traducción en la crisis del clero y los religiosos.

- En segundo lugar, abordaremos el sentido inverso: las repercusiones de la crisis del clero y los religiosos en la aceleración de las transformaciones sociorreligiosas.

- Por último, concluiré con la constatación de la hipótesis planteada: el carácter de la crisis del clero entre 1965 y 1972 como reflejo y factor del proceso de secularización.

\section{DEL CAMBIO SOCIAL Y ECLESIAL A LA CRISIS CLERICAL Y DE LA VIDA RELIGIOSA}

Nacido en una provincia de las más profundamente religiosas de España y en un pueblecito de vida agrícola, nada industrial, que a la sombra de su esbelta torre parroquial vivía sosegado y tranquilo, a pesar de los últimos coletazos del liberalismo decimonónico, aprendí desde niño a mirar en el sacerdote al representante de Dios y al comunicador de los divinos misterios (Sans 1965, 104).

El presbítero e historiador Ricardo García Villoslada, a quien pertenece el testimonio presentado, describe a la altura de los sesenta la pervivencia en su pueblo de una estructura religiosa profundamente arraigada a la tierra en la centenaria raíz del cristianismo sobre el suelo hispano. En este esquema, el sacerdote formaba parte de la cúspide de una sociedad que amaba, vivía, soñaba e imaginaba (pero también temía y se sentía coaccionada) a la sombra de la torre parroquial.

Su caso no era el único en España. A pesar de la primera oleada de secularización experimentada a finales del siglo XIX (Pérez-Agote 2012), de la "conflictiva secularización» (De la Cueva y Montero 2007) y de los múltiples espacios que mostraban un carácter prácticamente impermeable a la labor pastoral de la posguerra, la España - y buena parte de la Europa- de mediados del siglo XX aún se encontraba inserta en un esquema de cristianismo discursivo. Este concepto, definido por el historiador Callum G. Brown (2009, 12), remite unos patrones morales y sociales que continuaban definiéndose hasta ese momento por la etiqueta «cristiano", vinculación que confería una aceptación y valoración social a las prácticas que lo conformaban. Esta situación era más denodada en una España bajo régimen nacionalcatólico, en la que la evasión del control clerical constituía una odisea cuasi imposible (Abella 1985, 164-165) en una sociedad que alcanzó una de las mayores cotas de clericalización de la contemporaneidad (Botti y Montesinos 1998, 312). En este marco se efectuó la explosión de ingresos en los semi-

Fernando Sebastián (1970) y la Guía de la Iglesia en España de 1973 (Oficina General 1973). narios durante los años cincuenta, posibilitando la recuperación de las sangrías de los años treinta. ${ }^{5}$

Sin embargo, en la década de los sesenta, en la que se publicó el testimonio con el que comenzábamos, algo estaba cambiando. Mejor dicho, todo estaba cambiando en estos años de gran densidad transformativa (Taylor 2011; Richards 2013). En el caso concreto de España, el periodo entre 1965 y 1971 conformó la etapa que medió entre el cierre del Concilio Vaticano II y la celebración de la Asamblea Conjunta de Obispos-Sacerdotes en España, dos eventos que marcaron profundamente el debate posconciliar y que alentaron la expansión tanto de la opción reformista como de la rupturista en el seno eclesial. Pero también fueron años en los que el acceso a la sociedad de consumo y las consecuencias de la modernización económica se hicieron cada vez más presentes para amplios sectores poblacionales, con profundas repercusiones en el tejido social de España. Y, así pues, los cambios que se abrían presentaban, al menos, esta doble vertiente social y eclesial.

Por un lado, durante la última parte de la década de los sesenta las líneas de fricción ocasionadas por las transformaciones de la modernización social, económica y cultural se hicieron cada vez más profundas para los modos en los que la religión se había integrado en esa cotidianeidad aún recogida por García Villoslada. El cambio fue drástico. El aumento significativo del consumo respecto a la primera parte de la década se efectuó en paralelo a la subida de la renta per cápita, que creció desde 1961 a 1970 un 6,4 \% (Botti 2008, 181). En estos swingies sixties de The Beatles y de Marisol, España, tras la pobreza de la posguerra y del crecimiento económico rígido de los cincuenta, pasaba a convertirse en una de las diez potencias industriales mundiales, realidad bajo la que subyacían profundos cambios en la estructura social, como la ejemplificada por un movimiento territorial magnetizado hacia los polos de atracción industrial: 4,5 millones de españoles cambiaron de residencia entre 1960-1975 (Gracia y Ruiz 2004, 296).

Simultáneamente, emergía una juventud que progresivamente cortaba con la herencia del pasado; algunos, una masa importante de los estratos benjamines, se adherían a las contestación juvenil en espacios tan destacados como la Universidad, a la que llegaban los ecos del mayo del 68 francés; todos, se insertaban en unas estructuras sociales que - a ritmo de Love me do- diferían cada vez más intensamente del recuerdo postbélico y sus martirologías (Richards 2013).

Sin embargo, segunda vertiente, los significados y conceptos que formaban parte del imaginario católico entraron paralelamente en un periodo de cuestionamiento intraeclesial a medida que las aplicaciones del Concilio Vaticano II (1962-1965) ${ }^{6}$ adquirían envergadura (Montero 2008): el

5 El hecho de que la propia sangría de los años treinta, incrementada por los efectos de la guerra, se iniciase durante la época de Primo de Rivera - como mostró Severino Aznar - podría dar lugar a un interesante paralelismo entre esta situación y la posterior crisis del clero y los religiosos en medio de una España aún nacionalcatólica. Agradezco este sugerente comentario al informante externo de este artículo y lo incorporo para su consideración por parte de la comunidad científica.

6 Las ansias de reforma en el seno eclesial habían prendido en diferentes grupos con anterioridad al Concilio Vaticano II (AndrésGallego y Pazos 1999; Pelletier 2002; Cuchet 2018). Sin embargo, los estudiosos coinciden en afirmar que las reclamaciones reformistas y el 
rechazo a la pastoral de cristiandad o las implicaciones del papel de los laicos, entre otros debates del periodo posconciliar, fueron imprimiendo una impronta fundamental al núcleo propiamente religioso de ese cristianismo discursivo, transformándolo profundamente y sometiéndolo al cuestionamiento eclesial y social ante las profundas rupturas experimentadas.

Además, la mayor apertura al mundo por parte de la Iglesia, preconizada por el Vaticano II, facilitaba que los dilemas del contexto inmediato (cambio generacional, sociedad de consumo, etc.) se introdujesen y tradujesen al debate teológico y pastoral del posconcilio. Desde una Iglesia en cambio también se quería ofrecer respuestas ante los problemas del momento (McLeod 2007, 194), contribuyendo este afán a la denominada "secularización interna de la Iglesia» (De la Cueva 2018), proceso que abría al propio catolicismo a la temporalización (Koselleck 2003, 16-17) y a un «progresivo interesamiento en el mundo» (Pérez-Agote 2010, 319).

Desde el recuerdo de esta profunda interconexión entre problemas sociales y religiosos, la religiosa Cristina Gonzá$\mathrm{lez}^{7}$ enfatiza en sus respuestas a mi cuestionario la interrelación existente entre ambos vectores en sus primeros años de Universidad, en torno a 1967, que «estuvieron marcados por la gran diversidad de cambios que azotaron a la sociedad y a la Iglesia. Ambas estaban marcadas por los acontecimientos políticos, sociales y religiosos que se fueron sucediendo sin apenas tiempo para reflexionar sobre ellos». Era una crisis del catolicismo inserta en una crisis social de las estructuras religiosas del momento, y viceversa.

En medio de estas transformaciones se ubicó la crisis del clero y de los religiosos, que habían constituido una pieza esencial en los esquemas e imaginarios anteriores y jugaban un rol fundamental en las dinámicas de transmisión y reproducción de la religiosidad católica.

Por su destacada presencia en las obras del momento, cito a continuación tres de los vectores de la crisis que más frecuentemente aparecen en estos análisis y en los que se puede contemplar la citada doble vertiente de cuestionamiento eclesial y social: a) la profunda movilidad poblacional y la cada vez más evidente inviabilidad de la «civilización parroquial» y de la "pastoral de cristiandad», b) la crisis generacional y la ruptura con las herencias del pasado, tanto sociales como eclesiales, y c) la expansión de la desidentificación entre el clérigo y el religioso con su identidad y rol y, más en general, con la propia Iglesia que sustentaba ese modelo de vida clerical y religiosa. Mientras que las dos primeras cuestiones poseían un carácter más claramente ligado a la transformación social y su traducción eclesial, la última poseía un componente más perceptivo-simbólico pero no por ello menos real: la novedad experimentada en el seno eclesial alimentaba, valga la redundancia, el deseo de más novedad, ante el cual las anteriores estructuras devenían aceleradamente obsoletas y se expandía más denodadamente la sensación de ruptura efectuada por los cambios a) y b).

ansia de ruptura adquirieron una envergadura exponencialmente mayor a partir de la apertura del aula conciliar.

Cristina González (nacida en 1948), religiosa de la Asunción y responsable del Área de Formación y Espiritualidad de la CONFER en e momento de la entrevista (2018). Respuesta enviada por correo electrónico al autor, recibido el día 16 de octubre de 2018. a) La corriente migratoria de los años sesenta estaba reconfigurando el mapa de España a medida que vaciaba aquellas áreas rurales donde el cristianismo discursivo había pervivido de manera más intensa gracias a una mezcla entre el «prestigio y un estatus social elevado a tales vocaciones» (Duocastella 1971a, 131) y la escasez de medios para el sostén de todos los miembros de la familia. A lo largo de mi investigación he podido escuchar en repetidas ocasiones la misma historia: familias numerosas en el mundo rural, sin salidas laborales para todos los hijos, a las que un día llegaba un religioso para la "promoción de vocaciones» y, continúo con el testimonio del sacerdote Antonio Aradillas $(1977,60)$, se les exponía «a los niños y a sus padres las ventajas que tenía recibir una formación orientada hacia el sacerdocio o el claustro». Ante la falta de futuro para todos los hijos, «no resultaba difícil estimular tal convencimiento, ya que, en definitiva, los padres descubrían en la carrera del hijo la posibilidad del amparo y prestigio para el día de mañana». Esta es la historia que también narraba Albert Riba (2019), actual presidente de la Asociación de Ateos de Cataluña, en la entrevista que mantuvimos:

[El «reclutador» de los hermanos gabrielistas] iba por los pueblos de Castilla-León, Castilla-La Mancha, por los pueblos de todos esos sitios. $Y$, entonces, iba allí y hablaba con el cura del pueblo: «A ver, caquí hay algún chico que quisiera venir a nuestro seminario? Le enseñaríamos, le daríamos un oficio...». Entonces, el cura del pueblo, con toda su buena fe pero con muy mala leche también, pues le iba indicando las familias que estaban en una posición de mayor debilidad. ${ }^{8}$

Esta historia común nos ayuda a comprender parcialmente que en 1962 el 70,8 \% de los seminaristas hubieran iniciado su formación entre 10 y 12 años de edad (Acebal 1969, 172).

En este momento de los sesenta, no solo las condiciones económicas y materiales mejoraban y aparecían nuevas figuras de prestigio social que ya no eran religiosas, sino que, mientras el país dejaba de ser rural, las vocaciones continuaron concentrándose en los polos emigrantes del éxodo debido a la profunda integración idiosincrásica entre ese mundo rural en crisis y el catolicismo. Frente a los datos ofrecidos en la siguiente tabla sobre el mantenimiento de la extracción urbana/rural de los seminaristas durante los sesenta (Tabla 1), solo entre 1961 y 1965 las ciudades de menos de 10.000 habitantes (es decir, dos de las tres categorías de la tabla que concentraban entre ambas más del $70 \%$ de las vocaciones) perdieron 662.802 lugareños a favor de las ciudades de 10.000 habitantes (Fundación FOESSA 1966, 58). Espacios como los pueblos de la submeseta norte castellanoleonesa, una de las regiones con mayor aportación de vocaciones religiosas, se vaciaban progresivamente por medio de un saldo negativo migratorio de 466.000 personas entre 1961 y 1974 (De Riquer 2010, 636).

8 Albert Riba (nacido en 1947), presidente y fundador de Ateus de Catalunya y de la Unión de Ateos y Librepensadores en el momento de la entrevista (2019). En conversación con el autor, sede de Ateus de Catalunya (Barcelona), 21 de enero de 2019. 
TABLA 1

Porcentaje de seminaristas españoles por curso y tamaño de la localidad procedencia (en porcentaje)

\begin{tabular}{|c|c|c|c|}
\hline & $\begin{array}{c}\text { Localidad de } \\
\text { menos de 2.000 } \\
\text { habitantes }\end{array}$ & $\begin{array}{c}\text { entre 2.001- } \\
\mathbf{1 0 . 0 0 0}\end{array}$ & $\begin{array}{c}\mathbf{1 0 . 0 0 0} \\
\text { habitantes }\end{array}$ \\
\hline $1958-1959$ & 49,3 & 25,2 & 25,5 \\
\hline 1964 & 49,2 & 25,3 & 25,5 \\
\hline 1967 & 50,1 & 24,8 & 25,1 \\
\hline
\end{tabular}

Fuente: Hermet 1985, 37.

Aquellos lugares en los que el «clima religioso de la familia o por el ambiente de respeto y veneración que hacia el sacerdote reinaba en el mundo» (Tarancón en Mérida 1982, 75) eran los primeros en mostrarse con escasa proyección de futuro ante la nueva sociedad que despuntaba. Este cambio era, además, teóricamente reforzado a través del rechazo efectuado por la pastoral y la teología del posconcilio a las formas de cristianismo anteriores, que quedaron sintetizadas (y superadas teóricamente) en la expresión de régimen de cristiandad. El cristianismo auténtico y purificado que debía nacer en el posconcilio implicaba el cierre definitivo de todo modelo de cristiandad (González de Cardedal 1985), cuyas bases eran simultáneamente quebradas por las transformaciones socioeconómicas.

b) Como ha señalado Requena (1994), las problemáticas de la segunda mitad del siglo XX tuvieron en España un factor generacional evidente. En medio de un Régimen que se contemplaba como la España rediviva de los Reyes Católicos, entró en escena una generación de profunda voluntad rupturista con todo lo anterior, una generación de la que el filósofo Julián Marías (1984, 331-332) encuadró su fecha de nacimiento en torno a 1946. De nuevo, esta ruptura generacional se adentraba de lleno en los muros eclesiales. Máxime al calor del Concilio, que fue leído como ruptura con todo pasado, como una novedad en la propia Iglesia que alentaba las esperanzas de los miembros más jóvenes de su estructura.

A la altura de los años sesenta $-y$ como fruto de distintas dinámicas sociohistóricas - convivían en la Iglesia de España dos figuras sacerdotales y religiosas diferentes y prácticamente contrapuestas, sintetizadas a través de un binomio entre «mayores» y «jóvenes», entre los que habían sido ordenados antes de la guerra y los que provenían del aumento de cifras del seminario en los años cincuenta. Las muestras de esta división generacional son constantes en la documentación ${ }^{9}$ y han sido analizadas por distintas obras que han abordado las más amplias tensiones intraeclesiales del periodo (Montero 2009; González de Cardedal 2010; Laboa 2017).

En el cuestionario realizado a sacerdotes en el año de clausura del Concilio (Encuesta entre sacerdotes 1965), ${ }^{10} \mathrm{se}$ recogían las profundas diferencias entre generaciones. Este era el caso del testimonio de Javier Morales, quien explicitaba cómo existía entre los sacerdotes una brecha: «El clero "mayor" (prescindo de la edad) es vivencialmente estacionario y

9 Véase la pirámide de edades del clero de la España de los sesenta confeccionada por Duocastella $(1965,267)$.

10 FGE (3) $107.242 / 08990,8$. AGA. quizá incapacitado para asimilar vitalmente el Concilio. Sus estudios por lo general no comprometieron ni su conciencia ni su fé [sic.]», frente a un «clero joven - prescindo de edad- [que] estudia teología como una necesidad de elaborar su fé [sic.] y comprometer su conciencia» (ibídem, 6). Las diferencias entre el clero más joven y el clero mayor, que en la división de Javier Morales eran explícitamente las diferencias entre el clero tradicionalista y el rupturista-reformista, iban más allá de lo estrictamente religioso y se asemejaban a un conflicto de imaginarios diferenciales, ${ }^{11}$ en los que los curas más jóvenes, que no habían vivido directamente la guerra y cuyas expectativas estaban volcadas en el Concilio Vaticano II, contrastaban con «esos hombres, por lo general viejos, que se han formado en un ambiente de sólidas, compactas, tupidas creencias que para ellos son la realidad misma» (Ídem).

Las diferencias destacadas eran la muestra de que - con sus peculiaridades idiosincrásicas - también los dilemas de recepción de la anterior estructura religiosa se estaban reproduciendo en el seno de la propia Iglesia posconciliar. El teólogo Juan Antonio Estrada probablemente proporcione una de las claves de esta crisis generacional dentro de la Iglesia cuando indica: «Del mismo modo que los jóvenes buscaban emanciparse del hogar paterno, también una generación de religiosos, muy marcada por las reformas conciliares, buscaba insertarse en la sociedad" (Estrada 2008, 140-141) o, en palabras de un joven sacerdote de 1965: "Quiero ser tratado dentro de la Iglesia como uno que ha llegado a la mayoría de edad, no como un eterno niño». ${ }^{12}$ El deseo de emancipación y de novedad había alcanzado al seno eclesial y en él se fue expandiendo rápidamente hasta la Asamblea Conjunta Obispos-Sacerdotes de 1971, fecha en la que la opción reformista de Tarancón se impuso en la Iglesia española.

En el momento del inmediato posconcilio, este sector más joven, una «entera generación de curas que fueron ordenados de sacerdote justamente en el momento de apogeo del movimiento litúrgico» (Fierro 1968, 334), conformó el espacio eclesial que experimentó más intensamente los dilemas sobre la ruptura con la identidad heredada y en torno al desarrollo que debían dar a su rol de sacerdotes y religiosos. A este respecto, Fernando Sebastián, profesor a finales de los años sesenta en la Universidad Pontificia de Salamanca, señalaba cómo a los sacerdotes jóvenes, cuya vocación había nacido por diversos motivos ${ }^{13}$ en medio de la explosión de los seminarios en los cincuenta, "les impusieron la sotana a los doce, quince o dieciocho, cuando apenas tenían identidad existencial propia, [y] empezaron a preguntarse tardíamente por sus porqués» (Urbina 1981, 16-17), ya en un contexto en cambio. El testimonio del sacerdote rural cántabro Ernesto

11 La mayoría del clero joven optaba en la Encuesta por el socialismo como opción ideológica preferente, y mientras que entre los presbíteros mayores un $53 \%$ se mostraba molesto con las ideas avanzadas, el 59 \% de los jóvenes declaraba su desafección con las ideas tradicionales (Asamblea Conjunta 1971, 652).

12 Gomis, Joaquín. 1965. Como sacerdote, ¿qué esperas del concilio? Resultados de una encuesta. FGE (3) 107.2 42/08990, 8. AGA

13 Ante la pregunta "¿Cómo juzgarías tu decisión de ingresar en el seminario?» de la encuesta a los seminaristas, el 30,22 \% respondían que fue más bien un acto de sentimiento religioso, el 28,02 \% decía que fue una decisión inconsciente, como podía haber ido a otro lugar, el 23,13 \% decía que había sido una decisión tomada racional y conscientemente (Oficina General 1973, 108). 
Bustio relataba una idea parecida en los siguientes términos: "Yo recuerdo que me veía condenado a llevar sotana por los siglos de los siglos, cuando la tonsura [...] Y [me decía] "¿yo toda la vida tendré que ir así?"» (Seco y Bustio 2017), ${ }^{14} \mathrm{im}$ presión que repetía la religiosa María José Arana (2017), ${ }^{15}$ cuando después de los primeros votos empezó «a sentir que esto de una clausura tan estricta no tenía sentido, que el encerramiento excesivo tampoco".

c) Estas rupturas, en medio de una década de profunda transformación, coadyuvaban a la percepción de la invalidez total de los modos en los que la religiosidad en general y la vivencia del clero y los religiosos en particular eran experimentados. Era un corte con la sociedad anterior, tanto a nivel eclesial como social, que aparecía explícitamente en el posterior testimonio de un cura secularizado: «Fui ordenado para un tipo de sacerdote que hoy, creo, debería ser radicalmente distinto; para un mundo que ha cambiado profundamente, y yo no soy en absoluto aquel que a los veintitrés años decidió ser sacerdote» (Castro y Serrano, 1977, 16).

Consecuentemente, los testimonios y la documentación de este momento recogen la sensación de que entre el sacerdote y el mundo se establecía una contraposición difícilmente franqueable, que establecía un claro contrapunto con la anterior integración que habían poseído en la estructura social. Y los documentos de la Asamblea Conjunta apuntalaban estadísticamente esa impresión cuando mostraban cómo para el año 1969 el 56 \% de los presbíteros afirmaba que «lo que significa y exige el ser presbítero ha quedado bastante o muy indeterminado» en el contexto de la época. Entre los sacerdotes jóvenes, y en coherencia con lo afirmado en el punto b), el porcentaje ascendía hasta el $69 \%$. La diferencia generacional era aún más drástica en la cuestión de la desidentificación con la denominada Iglesia-institución. Mientras que el $26 \%$ de la media de todos los sacerdotes declaraba que no se sentía identificado con la Iglesia, en la división por edades el resultado devenía aún más revelador.

TABLA 2

Sacerdotes no identificados con la Iglesia-institución en 1969-1970

\begin{tabular}{|l|c|c|}
\cline { 2 - 3 } \multicolumn{1}{c|}{} & \multicolumn{1}{c|}{$\begin{array}{c}\text { Número de } \\
\text { respuestas }\end{array}$} & $\begin{array}{c}\text { \% de no } \\
\text { identificados }\end{array}$ \\
\hline Menos de 30 años & 934 & 50,2 \\
\hline De 30 a 39 años & 1.765 & 38 \\
\hline De 40 a 49 & 804 & 23,3 \\
\hline De 50 a 64 años & 279 & 9,7 \\
\hline Más de 64 años & 122 & 6,9 \\
\hline
\end{tabular}

Fuente: Asamblea Conjunta $(1971,605)$. Nota: proviene de la pregunta 1058 (muestra 14.613 sacerdotes) de la Encuesta-consulta realizada en 1969-70.

14 Avelino Seco y Ernesto Bustio son sacerdotes de la diócesis de Santander. Bustio (nacido en 1937) gestiona el Albergue del Abuelo Peuto en un área rural de Cantabria. Seco (nacido en 1941) se encuentra vinculado a una parroquia santanderina. En conversación con el autor, Güemes (Cantabria), 21 de marzo de 2017.

15 María José Arana (nacida en 1943), teóloga feminista y religiosa del Sagrado Corazón. Ha sido copresidenta del Fórum Ecuménico de Mujeres Cristianas. En conversación con el autor, Getxo (Vizcaya), 22 de marzo de 2017.
En esta mayoritaria desidentificación con la Iglesia-institución por parte del clero joven y en el más generalizado rechazo del presbiterado español hacia la figura sacerdotal se fraguó lo que distintos documentos revelaban como el nudo gordiano de la crisis sacerdotal y religiosa, que fue también una crisis del modelo eclesial. Una carta entre el jesuita Antonio Luis Marzal y el padre Arrupe sobre los motivos de petición de secularización del primero nos sirve de ilustrativo ejemplo. El entonces sacerdote señalaba que incluso aquel contexto de «la evolución real de la Iglesia oficial, y sobre todo de la Compañía, que se presenta tan positiva», no conseguía convencerle de que

\begin{abstract}
las formas jurídicas del sacerdocio y de la vida religiosa me parece que en la actual Iglesia, ya no son, y es posible que ya no puedan ser, la expresión de las intuiciones de la fe que trataron de encarnar. Me parece que, por el contrario, son solo el fruto de un acarreo histórico que hoy, más que revelar, se prestan a velar el rostro de Dios en la historia, según la expresión del Vaticano II. ${ }^{16}$
\end{abstract}

Los informes apuntaban hacia esta desidentificación para explicar el aumento del número de salidas tanto de los seminarios y noviciados como de la vida sacerdotal y religiosa, principales síntomas de la crisis en este sector, y que se añadían al continuo decrecimiento durante el periodo de los ingresos en los centros de formación de la Iglesia, cuya extracción dependía de un mundo rural en sangría. Como recogía Miret Magdalena, para 1966 el número de sacerdotes ordenados anualmente había bajado de 970 a 616, y el número de seminaristas que abandonaban su formación por año había aumentado de 2.800 a 3.857 (Miret 1968, 183).

TABLA 3

Evolución del número de seminaristas diocesanos en España (1964-1972)

\begin{tabular}{|c|c|}
\hline Año & Número de seminaristas mayores \\
\hline 1964 & 8.233 \\
\hline 1965 & 8.079 \\
\hline 1966 & 8.079 \\
\hline 1967 & 7.535 \\
\hline 1968 & 7.106 \\
\hline 1969 & 6.605 \\
\hline 1970 & 4.978 \\
\hline 1971 & 4.822 \\
\hline 1972 & 3.413 \\
\hline
\end{tabular}

Fuente: Domínguez Rojas 2001, 40-41.

Para los sacerdotes y religiosos esta desidentificación condujo crecientemente hacia la secularización canónica del clero o al abandono de la congregación por parte de los religiosos. Entre las distintas motivaciones, subyacía la línea de fondo que venimos explorando en estas páginas: la insatisfacción ante las estructuras clericales recibidas, dentro de un más amplio rechazo de la Iglesia en sí, que conformaron entre ambas, según el sacerdote Federico Sopeña (1970, 126-127), la causa primera de secularización en el clero joven.

16 Carta de L. Marzal al padre Arrupe explicando los motivos para abandonar la Compañía. 5 de junio. FGC, caja 38, carpeta, 6, subcarpeta «Alegría». AESI-A. 
Así pues, la cifra de secularizaciones canónicas aumentó a lo largo de toda la década tanto en España como en otras iglesias de la Europa occidental, alcanzando el 1,54 \% sobre el total de los sacerdotes diocesanos en España, el 1,35 \% en Francia, el 0,85 \% en Italia y el 0,56 \% en Bélgica entre 1962$1968 .{ }^{17}$ En perspectiva comparada y a la altura de 1968 , la estadística situaba a España en el mayor número proporcional de salidas del espacio de Europa occidental. Y las cifras para el caso hispánico «habían hecho circular una abundante fantasía en no pocos sectores, dando la impresión de que asistíamos a una verdadera desbandada de sacerdotes» (ABC 1969, 30). En 1970 se tuvo que crear una oficina para sacerdotes secularizados con el objetivo de "paliar el grave y nuevo problema pastoral que ha surgido con la secularización de sacerdotes" (ABC 1970, 36).

El descenso fue todavía más acentuado en el caso de los religiosos. En apenas 5 años se redujo en un $50 \%$ el número total de novicios en España, con repercusiones potenciales también para la secularización del propio sector de la enseñanza, en el que particularmente se encontraban presentes estas congregaciones.

Pero, igualmente, si sumamos el grueso de salidas de profesos a la pérdida de novicios, las cifras adquirían un perfil más drástico. Entre 1966 y 1971 se elevó a 2.639 el número de religiosos que había abandonado de forma definitiva la congregación, cifra que alcanzaba el 9,4 \% del total de religiosos (Vázquez, Medín y Méndez 1973, 170). En el caso de la Compañía de Jesús, baluarte de la restauración católica en España, la década de los años sesenta fue especialmente dramática. Y más que la década, tenemos que subrayar que la intensidad cuantitativa se concentró en los últimos cinco años de los sesenta. La Compañía de Jesús perdió 962 miembros en el periodo, lo que suponía un 20,39 \% menos de efectivos en 1970 respecto a la cifra de 1965 (Anuario de la Compañía de Jesús 1960, 1965, 1970), cifra que - a su vez- se sumaba al fuerte decrecimiento que experimentaban otras congregaciones e institutos de vida religiosa masculina. ${ }^{18}$

TABLA 4

Evolución del número de novicios en España, y por comunidades religiosas destacadas (1965-1972)

\begin{tabular}{|l|c|c|}
\cline { 2 - 3 } \multicolumn{1}{c|}{} & 1965 & 1972 \\
\hline Maristas & 222 & 76 \\
\hline Franciscanos & 82 & 41 \\
\hline Agustinos religiosos & 88 & 74 \\
\hline Dominicos & 111 & 43 \\
\hline Escuelas Cristianas (La Salle) & 221 & 51 \\
\hline Salesianos & 269 & 113 \\
\hline Claretianos & 91 & 19 \\
\hline Total de novicios en España & 2.333 & 1.053 \\
\hline
\end{tabular}

Fuente: Guías de las comunidades religiosas (Confederación Española de Religiosos 1966a, 1972).

17 Boulard, Fernand, sf. Manuscrito con datos estadísticos del canónigo Boulard. Fondo 14 "PP-Chanoine Fernand Boulard», carpeta 4 «Sacerdocio». Centre National des Archives de I'Eglise en France (París, Francia).

${ }_{18}$ En los datos proporcionados no se diferencia entre fallecimientos y salidas. Sin embargo, lo especificado en otros informes y fuentes nos hace pensar que la excepcionalidad de la reducción en estos años fue debida en gran medida a la cuestión de los abandonos de la vida religiosa, deviniendo la cuestión del fallecimiento una causa más central en las décadas posteriores.
Por su parte, las cifras e informaciones relativas a la vida religiosa femenina, tanto activa como contemplativa, son considerablemente más escasas y fragmentarias que para los varones. Las religiosas no atrajeron la atención que suscitaron los problemas del mundo clerical, una realidad que se explica también a partir de su posición más periférica en el organigrama de la Iglesia Católica. Sin embargo, y a partir de la poca información disponible al respecto, se revelaba la importante reducción de su número; situación que quedaba acreditada en datos como la elevada cantidad de dispensas de la vida religiosa femenina que se solicitaron solo en un solo año (494 peticiones de salida en 1972), así como en la reducción de efectivos totales (entre novicias y profesas) de las comunidades de religiosas femeninas: de 80.990 para 1965 a 65.092 para 1972 (Confederación Española de Religiosos 1966b; Vázquez 1976, 629).

\section{DE LA CRISIS CLERICAL Y DE LA VIDA CONSAGRADA AL CAMBIO SOCIAL Y ECLESIAL}

Hasta este punto hemos expuesto cómo las transformaciones sociales y eclesiales abiertas en la década de los sesenta afectaron al sector del clero y de los religiosos. Pero desde la crisis en este espacio eclesial hacia la sociedad en su conjunto se puede establecer otro vector de aceleración del propio proceso de secularización, particularmente a través del impacto de las transformaciones experimentadas por el clero y los religiosos en un imaginario de la población aún impregnado de cristianismo discursivo.

Ante la sensación de crisis, tanto de la religiosidad como del sector encargado de su gestión y transmisión, la denominada como «secularización interna de la Iglesia» tuvo una variante expansiva hacia la sociedad por medio del intento de adaptación del catolicismo a los patrones socioculturales que empezaban a emerger.

En este momento, los curas y religiosos desidentificados y críticos continuaban siendo responsables pastorales de una población en la que, aún a finales de los sesenta, las transformaciones, siendo amplias en su alcance, prendieron de manera desigual. Además, no solo la institución católica había poseído y poseía una importante presencia en el tejido social del país, sino que, como Comas $(2006,40)$ señala, precisamente el tardofranquismo supuso el cénit de la popularidad eclesial en la vida pública española gracias a la atención mediática a una Iglesia en vías de renovación (Martín Descalzo 1976, 452). De tal modo, este proceso de secularización interna de la Iglesia se extendió desde las rupturas experimentadas por los miembros eclesiales respecto a la vivencia del catolicismo hacia otras rupturas de carácter más general, de «mentalidades y vidas en la Iglesia» (Ordóñez 1970, 5).

En su interacción con la sociedad, el intento de transformación de la religiosidad católica se situaba en el límite entre la generación de un cristianismo más adaptado a una sociedad secular y la potencial disolución de la religiosidad en el tejido social resultante de la modernización. Esta tensión era apuntada por distintos documentos a través de la bifurcación que planteaban entre las posibilidades que brindaba la secularidad para la purificación del cristianismo y la amenaza de que, por medio del afán por la adaptación, se acabara por difuminar la cuestión religiosa que había alum- 
brado la motivación inicial, es decir, "que se diluya "la sal" en una mundanización creciente» (Cardenal 1972, 28); una delgada línea que, a juicio del jesuita José Luis Pintos, fraguaba distintos caminos: «O hacia una renovación auténtica del cristianismo promovida principalmente por miembros activos de las asociaciones apostólicas en profundo trance de revitalización, o hacia un aburguesamiento de toda actitud cristiana, o hacia un humanismo reductor de toda experiencia de fe religiosa» (Pintos 1968, 397).

Desde las premisas de esta tensión y por medio de la citada presencia - tanto social como mediática- que la Iglesia aún poseía, los testimonios del momento recogían dos líneas fundamentales de potencial expansión de la secularización a partir de la crisis del sector religioso y clerical:

a) La crítica al rol sacerdotal y religioso realizada por los mismos se encontraba frente a una valoración más tradicional de sus funciones en parte de la población, y contribuía a que los fieles se desclericalizasen junto a los pastores.

b) Además, en la revisión de su propio rol, los sacerdotes y religiosos también propugnaban una más amplia crítica a la religiosidad tal como se había vivido en las condiciones catalogadas como de régimen de cristiandad, revisión que - de nuevo- se encontraba tanto con b1) aquellos imaginarios a los que todavía no habían llegado los dilemas de las trasformaciones sociales como con b2) sectores ya insertos en un cambio de parámetros socioculturales, que fueron paradójicamente potenciados por los propios esfuerzos de adaptación religiosa por parte del clero y los religiosos.

a) Sobre la base de desidentificación de los presbíteros y de los religiosos con su propio rol e identidad, se llevaron a cabo toda una serie de replanteamientos profundos de la función sacerdotal/religiosa y su inserción en la vida cotidiana, ya que en gran parte de los afectados por esta crisis se ensayaron diferentes alternativas antes de alcanzar la secularización definitiva en sentido canónico (Vázquez 1976, 609). Era el intento de gestación de soluciones y de adaptaciones que emergía, como señalaba Tarancón, de la «conciencia de culpabilidad por ese carácter sagrado que ha tenido hasta ahora su estado y quisieran disimular, al menos, su consagración, evitando cuidadosamente todo lo que pudiera singularizarlos o distinguirlos» (citado en Moreno 1971, 46).

En palabras del que fuera sacerdote en activo, Andrés Muñoz, ${ }^{19}$ una de las primeras consecuencias del rechazo del anterior modelo hacia la recreación de una nueva figura sacerdotal era algo tan sencillo como la supresión del beso en la mano del sacerdote o el uso del tuteo, que rompían tanto con la dinámica relacional clero-laico como con todo un vocabulario que se encontraba envuelto de "cursilería que hacía llamar al obispo "nuestro amantísimo Prelado"», como recordaba el sacerdote Federico Sopeña $(1970,23)$. El tuteo se convirtió en uno de los primeros símbolos de elimi-

19 Teresa Cortés (nacida en 1954) fue coordinadora general del Movimiento pro Celibato Opcional, y su marido, Andrés Muñoz (nacido en 1942), fue sacerdote activo y actualmente es también miembro de la plataforma. En conversación con el autor, Getafe (Madrid), 16 de septiembre de 2018. nación verbal de una diferencia que aún se podía encontrar físicamente marcada por la vestimenta clerical.

A este respecto, en un artículo de Razón y Fe se señalaba que en la civilización parroquial el católico poseía la impresión inmediata de lo sagrado por medio del traje talar y el edificio de la iglesia (González 1962, 137), símbolos de la presencia del imaginario católico en la vida cotidiana. Otro grado más en este progresivo difuminado de la identidad clerical se efectuó, precisamente, en torno a esa vestimenta diferenciadora. Parte de los propios presbíteros, incluso antes de la autorización para el abandono de la sotana, ya habían mostrado una creciente relajación de la norma relativa a la vestimenta (Abella 1985, 169), que en la época del Concilio se tradujo en un desuso masivo del traje talar por el clergyman o para vestir sin ninguna distinción. Como indicaba ilustrativamente Andrés Muñoz, del movimiento MOCEOP: «El Vaticano II me había dado permiso para vestir el traje talar que llamaban, con el clergyman y cuellecito. $Y$ yo empecé así, pero, a los tres o cuatro meses, pues llegó el verano, y ya pues iba normal, como la gente normal» (Cortés y Muñoz 2018).

El cambio fue tan rápido y drástico que las generaciones nuevas de sacerdotes directamente empezaban su vida presbiteral sin ningún tipo distinción; una rapidez en la transformación que explica que en 1966, solo un año después del cierre del Concilio, este asunto se hubiese convertido en una temática presente en los medios y en los debates eclesiásticos del momento. "Los cambios en el traje talar ha sido uno de los temas debatidos en la reciente conferencia de la permanente del episcopado español, celebrada en Madrid", señalaba $A B C(1966,76)$ en este periodo. La intensidad de la transformación en un corto espacio de tiempo se recogía también en los datos de la Encuesta-consulta al clero realizada en 1969-70. En este año, los sacerdotes que vestían directamente al margen de las disposiciones de la Conferencia Episcopal ${ }^{20}$ superaban con creces a los presbíteros que utilizaban la indumentaria "oficial»"21 (Oficina General 1973a).

Estos «pequeños cambios puntuales (por ejemplo, el abandono del hábito) pueden tener consecuencias imprevisibles a largo plazo» (Estrada 2008, 145), y en palabras de Andrés Muñoz: «De todo eso salimos, y al final yo me fui despojando. Yo salí hasta con sotana, y el día en que me desensotané - si se puede decir así- la vida se me hizo un poco menos oscura, la sotana era negra» (Cortés y Muñoz 2018).

Hacia ese futuro «menos oscuro» y más desclericalizado también se establecían caminos alternativos a las entendidas hasta entonces como tareas y funciones que se esperaban del presbítero (Gálvez 1971, 46), a medida que la dedicación exclusiva a la actividad sacramental y pastoral, principal labor presbiteral, acababa por devenir «insufrible» para sacerdotes como Mariano Gamo, cura en el barrio obrero de Moratalaz (Madrid) (Centeno, Díez y Pérez 2009, 218).

Así pues, desde este deseo de identificación más intenso con «el pueblo», surgían sacerdotes que daban un paso más

20 Las opciones de «traje que más se adapta al ambiente» (40\%) y el traje seglar (18,6\%).

21 La sotana (escogida por el $20,7 \%$ de preferencia) y el clergy$\operatorname{man}(16,3 \%)$. 
con otra inserción en la estructura social: la incorporación al mundo laboral, ${ }^{22}$ en la que podían llegar a descubrir incluso que se encontraban en un estadio «más realizado y más persona cuando me implicaba en asuntos temporales y más insatisfecho y molesto cuando tenía que realizar las funciones estrictamente sacerdotales ${ }^{23}{ }^{23}$ Una de las respuestas más populares a esta contradicción se dio en la figura de los curas obreros, que se expandió en este momento hasta alcanzar la cifra de más de mil presbíteros con ocupaciones laborales (Centeno, Díez y Pérez 2009), cuyas repercusiones sociales y mediáticas excedieron con creces el número de representantes de esta forma de entender el sacerdocio. Además, los curas obreros constituían la prueba evidente de una paralela politización durante los años sesenta en parte del sector clerical, que no solo superaba la figura del sacerdote sacramental para involucrarse en el mundo laboral, sino que en algunos casos se adentraba incluso en la lucha política contra un Régimen paradójicamente catalogado como católico (el caso de Paco García Salve y su presencia en Comisiones Obreras y en el Comité Central del Partido Comunista de España).

Por otra parte, a nivel interno de la propia Iglesia nunca de manera tan explícita se ha discutido en la contemporaneidad la cuestión del celibato de los sacerdotes católicos de rito romano, ${ }^{24}$ cuyo cuestionamiento alcanzó en este momento a una amplia parte del clero y de los religiosos. ${ }^{25}$ De hecho, la curiosidad que suscitó en la prensa generalista favoreció que se expandiera la difusión del debate a capas más amplias de la sociedad a través de las diferentes polémicas que se estaban experimentando en la Iglesia católica internacional, como fue el caso del Concilio Pastoral de Holanda. Esta reunión postconciliar de la Iglesia neerlandesa efectuó explícitamente una petición de reconocimiento del celibato opcional al papado y supuso un evento que fue ampliamente relatado en el contexto español por $A B C$ a través de entrevistas a los protagonistas y noticias en este diario, como la que fue encabezada por el significativo título: «La crisis actual del catolicismo holandés - hábilmente explotada por publicaciones sensacionalistas - apasiona a toda Europa» (Alcalá 1967, 33). La propuesta del Concilio pastoral holandés y el tema del celibato opcional fueron frenados en seco desde Roma en una época de temprano inicio de la «rectificación» de ciertos debates posconciliares, entre los cuales el celibato sacerdotal supuso una de las primeras líneas rojas.

22 En la Encuesta-consulta ante la pregunta «¿Cree Vd. que por la evolución social moderna se justificaría que el sacerdote asumiera también actividades como promotor social, maestro, obrero...?», las respuestas se distribuían entre un 27,9\% «no, nada»; un 7,7\% «muy poco»; 9,2 \% «poco»; 17,1 \% «bastante»; 15,4\% «mucho»; 19,3\% "muchísimo», (no responden, no contestan el 3,4 \% de los encuestados) (Oficina General 1973, 87).

${ }_{23}$ Según el testimonio de Benjamín García Sanz, que fue cura en Canalejas de Peñafiel (Valladolid) antes de solicitar su secularización (Castro y Serrano 1977, 28).

24 Actualmente este debate se ha reabierto a partir del Sínodo de la Amazonía (octubre de 2019).

25 Ante la afirmación realizada a los sacerdotes: «Está usted de acuerdo con que el celibato sacerdotal debiera convertirse en una elección libre dentro del sacerdocio", las respuestas se distribuían de la siguiente manera: «No nada, ninguno» $(40 \%)$, «muy poco» $(3,5 \%)$, "poco» $(3,7 \%)$, «bastante» (10\%), «mucho» $(10,1 \%)$, "muchísimo» $(27,1 \%)$, «no responde, no contesta» (5,6 \%) (Oficina General 1973, 90).
En definitiva, un sector de los sacerdotes y religiosos del momento constituyeron a través de sus adaptaciones parte de la avanzadilla del cambio, con unas recreaciones de su identidad sacerdotal que en ocasiones excedían la mentalidad católica aún presente en parte de la feligresía. Y, de tal modo, las transformaciones que promovieron bajo la premisa de un sacerdocio más evangélico no solo se alejaban indudablemente del modelo de "los sacerdotes antiguos [que] mantenían una pureza ritual, una distancia de la población que les capacitaba para ser negociadores eficaces con el mundo sobrenatural» (Christian 1978, 200), sino que chocaban con sectores sociales para los que el cambio, aunque a un ritmo frenético, todavía era desigual en su expansión. ${ }^{26}$ En este encuentro diferencial entre mentalidades se difuminaban de manera más clara los modos en los que la religión había estado presente hasta el momento, que dificilmente habían imaginado que los curas se planteasen el celibato, formaran parte de sindicatos o abandonaran masivamente su ministerio. La secularización interna de los planteamientos eclesiales en la figura del clero y los religiosos antecedía, pues, a la secularización social de los imaginarios. Y la desclericalización de su identidad también desclericalizaba la percepción de la población.

b) A su vez, este cuestionamiento de la figura del clero y de los religiosos, secularizando progresivamente su rol y función, y el choque con las mentalidades que seguían insertas en modos tradicionales se englobaban dentro de una revisión más amplia de la propia religiosidad católica, efectuada en muchas ocasiones por los propios clérigos y religiosos, especialmente en aquellos más desidentificados y rupturistas con las estructuras existentes hasta el momento.

Estos replanteamientos de su rol e identidad tuvieron como trasfondo teórico un más general cuestionamiento sobre el papel del cristianismo en una sociedad secularizada, que exigía, a ojos de los más críticos, la denominada como desmitologización de la religión. La hondura teológica del debate sobre un cristianismo desmitologizado nos puede hacer pensar su carácter minoritario. Sin embargo, un informe anónimo y confidencial del Archivo de Álvarez Bolado, documento que posiblemente fuera realizado hacia el inicio de los setenta, ${ }^{27}$ explícitamente señalaba que "estos constituyen temas de los que son conscientes pocos pero que afectan a muchos». ${ }^{28}$

De este modo, el sector clerical y religioso más crítico, que buscaba desempeñar más auténticamente su función, y unos cristianos activos que propugnaban la necesidad de la adultez del creyente y de la purificación religiosa no solo gestaron un cristianismo más netamente moderno y adaptado a la exigencias de una sociedad secular, sino que también contribuyeron a la erosión de las anteriores estructuras religiosas, que mientras en unos casos fueron sucedidas por una renovación de la vivencia religiosa, en otros espacios condujo hacia una suerte de cristianismo descompuesto y fragmentado (De Certeau y Domenach 1974) o hacia el va-

26 Aún en 1971 , un $34,1 \%$ de los habitantes de Castilla la Vieja respondían que querían que el sacerdote se situara dentro de una dimensión mítica de «ser sagrado y diferente de nosotros» (Duocastella 1971b, 36).

27 Cita como máximo documentos del año 1971.

28 Enunciado de algunos problemas que vive hoy la Iglesia. sf. AESI-A. FAB, caja 68, carpeta 1. 
cío religioso, contribuyendo paradójicamente a la propia secularización como "consecuencia imprevista de la acción», en términos sociológicos.

En primer lugar (b1), las tradiciones religiosas que se deseaban transformar eran tan extrañas para el mundo postconciliar rupturista como aún cotidianas para muchos de los católicos. El esfuerzo de propagación de una lectura más crítica de la religiosidad cristiana, en la «que existe Dios y Jesucristo y poco más...Que se quieran unos a otros», ${ }^{29}$ como señalaba un jesuita joven tras asistir a finales de los sesenta a un curso titulado Hacia un verdadero cristianismo, se encontraba frente a piezas del imaginario católico que continuaban arraigadas, como se puede ejemplificar - por ejemplo- no solo en la anteriormente citada cuestión del rol del sacerdote, sino también en el impacto que conllevó la relectura de las tradiciones y prácticas religiosas.

En este sentido, el rezo del rosario, ligado a la figura de María, ha surgido en numerosas ocasiones a lo largo de mi investigación como ejemplificación del dilema entre tradición y adaptación. En diferentes testimonios y documentos irrumpe esta particular devoción mariana como símbolo de esa religiosidad pasada y pesada con la que se quería cortar por parte de los sectores más críticos, como símbolo de una práctica rutinaria y tradicional difícilmente adaptable a la sociedad secular por su teórica vinculación con un mundo pre-moderno. Sin embargo, los sacerdotes cántabros Seco y Bustio (2017) describen con claridad en la entrevista que mantuvimos la reacción de parte del pueblo ante la eliminación del rosario en una parroquia en la etapa posconciliar, momento en el que este continuaba integrado a su vez dentro de un imaginario vital más amplio: "tomar unos vinos», «cerrar las tiendas». En sus palabras:

Yo conocí en aquellos momentos en que todavía lo religioso vertebraba en algún sentido la vida de los pueblos, en que la celebración de la misa servía para encontrarse a la gente, para hacer un alto en el camino de la vida social, para tomar después unos [vinos] blancos juntos. En algunos sitios incluso por la tarde se rezaba el rosario y todavía había mucha gente que iba. Y el cortar [...] yo recuerdo, por ejemplo, en aquel pueblo [cortar] con el rosario al principio chocaba. Eso era tan fuerte, que era como algo propio de cada pueblo, que los bares y las tiendas cerraban en los momentos de los oficios religiosos.

La práctica del rosario, entre otras cuestiones, formaba parte aún de un imaginario más amplio para ciertos sectores de la población, y la erosión del mismo suponía un impacto para los modos de recreación de la religiosidad en la cotidianeidad. Distintas voces narraron los efectos potencialmente secularizadores de esta labor de traducción y adaptación desde la común impresión de que con la transformación se promovía una desacralización ${ }^{30}$ de los imaginarios en espacios donde todavía no habían llegado las dinámicas de modernización económica y social, pero donde sí habían lle-

29 Carta al Instituto Universitario de Teología Instituto Fe y Secularidad sobre el curso de ateísmo y cristianismo. 1970. AESI-A. FGC, caja 26, carpeta 1 «polémicas».

30 El artículo que abría el monográfico de Iglesia Viva de 1969 sobre secularización se titulaba, precisamente, «Desacralización y secularización». gado previamente sacerdotes y religiosos que asumieron el imperativo de la necesidad de cambio.

A este respecto, el estudio antropológico del valle del Nansa reflejaba de manera descriptiva y sugerente las reacciones que se producían entre el deseo de adaptación de los curas posconciliares y el imaginario del cristianismo rural en una zona remota de la entonces provincia de Santander. ${ }^{31} \mathrm{EI}$ observador, el antropólogo William Christian, señalaba distintos cambios en prácticas arraigadas hasta el momento, como - por ejemplo- que «el dinero del cepillo que se empleaba en misas por las almas del purgatorio (procedente de promesas, tanto para la salvación de las almas como por las necesidades temporales y eternas de los aldeanos) [fuera] al fondo diocesano de caridad" (Christian 1978, 202). Para el antropólogo, transformaciones como la citada constituían una disolución progresiva de lo sagrado en las cosmovisiones. El estudioso atribuía claramente el origen de estos cambios a los sacerdotes, especialmente los más jóvenes, a los que denomina de la "reforma» (de nuevo, la repetición del cura conciliar como el cura joven y en ruptura), que cambiaban el antiguo imaginario católico por nuevas traducciones y adaptaciones: «el concepto de Cristo como amigo o modelo, si bien no encuentran objetable la noción de María como madre [...] En última instancia, la posición de los sacerdotes jóvenes les conduce a negar la doctrina del pecado original y a revalorizar la naturaleza humana, que consideran que participa de la de Cristo» (Ídem).

Desde una clave personal, Avelino Seco, sacerdote de Santander, subrayaba en la entrevista las consecuencias de las distintas dinámicas de transformación, cuyo objetivo inicial había sido la revitalización de la espiritualidad hacia «un tipo de religiosidad que va más unido a la vida, dando menos importancia al encuentro religioso simplemente como hábito» (Seco y Bustio 2017). Sin embargo, en la misma entrevista continuaba señalando que los que se imbuían de ese espíritu preconizado por los curas posconciliares iban «a misa menos que antes, cuando han descubierto grupos» (Ídem).

Ambos testimonios, el estudio antropológico y la entrevista, concluían de una manera pareja: se estaba eliminando un modelo de estructuración basado en la tradición -que también se veía afectado por los cambios migratorios y la implantación de la sociedad de consumo- a golpe de renovación y sin claramente edificar las bases de un nuevo sistema, lo que fomentaba una desestructuración mayor (Ídem). $\mathrm{Y}$, como señala un informe realizado por Rogeli Duocastella (1971b, 75), auguraban una larga agonía «mientras no se realicen más allá de imágenes sacerdotales, nuevos tipos de cristianismo».

En segundo lugar (b2), frente al sacerdote y el religioso como guardián cotidiano de la ortodoxia y de la fe, la conciencia personal devino el depósito donde se debía confrontar la religiosidad para los sectores más abiertamente reformistas-rupturistas. Esta variante particular de la "ética de la autenticidad», del subjetivismo que según Charles Taylor (2015) se expandía denodadamente en este momento, marcaba un claro contrapunto con el concepto de tradición, trasladando el énfasis desde la ortodoxia a la autenticidad de la fe vivida y la ortopraxis. Entre los sacerdotes y religiosos que optaron más claramente por la vía reformista-

31 Aunque la publicación consultada es del año 1978, el análisis se realizó en 1969 (Christian 1978, 200). 
rupturista y los jóvenes que más experimentaban el nuevo reclamo cultural subjetivista se establecían canales de potenciación de los efectos. Es decir, si el objetivo de los agentes pastorales se centraba en una revalorización evangélica de la norma en torno al sujeto, el efecto se incrementaba a través de la recepción ofrecida por una generación joven en ruptura pero aún conectada con la Iglesia.

A este respecto, el informe de ISPA ${ }^{32}$ realizado en los colegios de la Iglesia mostraba cómo entraban en interacción estas dos realidades. Por un lado, en los colegios de la Iglesia en los que la misa diaria era obligatoria en 1968, la asistencia al oficio eucarístico alcanzaba el $75 \%$ del alumnado. En las escuelas donde no era obligatoria esta asistencia, pero sí recomendada, las cifras ascendían únicamente al 10-20 \% del alumnado (ISPA 1971, 195-199).

De otro lado, eran precisamente los sacerdotes menores de 45 años -aquellos que más desidentificación mostraban con la Iglesia y más cercanos se situaban a los esfuerzos de adaptación y de traducción- los que representaban el $75 \%$ de los profesores de religión de los propios colegios de la Iglesia en 1968, cuyos alumnos estaban en proceso creciente de «materialización», según el informe de ISPA (1971)..$^{33}$ Este clero joven, visto por la juventud como «en desacuerdo con la propia Jerarquía y disconforme con el orden político-social y de la nación», constituía un sector del sacerdocio del que poseían muy buena opinión, dado que el «78 \% de los encuestados [también entre jóvenes de colegios de la Iglesia] está de acuerdo con ellos, mucho o totalmente» (citado en Comisión Episcopal de Pastoral 1975, 149).

A partir de los datos y materiales analizados, podemos afirmar que la profunda crisis que experimentaba el sector clerical y religioso contribuyó a la paralela transformación sociorreligiosa a través de sus esfuerzos por la generación de un cristianismo y un sacerdocio/vida religiosa más auténticos y capaces de dialogar con la secularidad en ciernes, pero que también fomentaron, como «consecuencia imprevista de la acción», una mayor desestructuración del contenido conceptual de la religiosidad católica por medio de la promoción del subjetivismo y de la erosión de la vivencia tradicional tanto del rol del clero y de los religiosos como de la religiosidad católica en general. Quizá no podía ser de otro modo, y que el empeño de un cristianismo "más purificado» hiciese inevitable la quiebra total del anterior cristianismo discursivo, que - a su vez - también estaba siendo erosionado irremediablemente por los profundos cambios socioeconómicos.

\section{CRISIS DEL CLERO Y DE LOS RELIGIOSOS: REFLEJO Y FACTOR DEL PROCESO DE SECULARIZACIÓN EN ESPAÑA}

En el presente artículo nos hemos adentrado en una profundización de la comprensión del proceso secularización en España desde una perspectiva sociohistórica a través de una vertiente del mismo, la crisis del clero y de los religiosos. $Y$ hemos tratado de efectuar nuestra aproximación como esta disciplina acostumbra a hacer: a través de casos concretos y contextualizados, a partir de los documentos y

32 Centro de estudios sociológicos sobre la religiosidad. Fue una iniciativa pionera en España, dirigida por el sacerdote Rogeli Duocastella.

33 La fecha de publicación es 1971 , pero la encuesta se llevó a cabo en 1967-1968. de los agentes históricos que tejen y destejen en la rueca del tiempo.

Tras comenzar en un estadio en el que los imaginarios sociales continuaban imbuidos de cristianismo discursivo a la altura de la mitad del siglo XX, hemos realizado un análisis de la crisis del clero y de los religiosos experimentada entre el cierre del Concilio Vaticano II (1962-1965) y el fin de la Asamblea Conjunta (1971), periodo en el que se expandieron más denodadamente tanto corrientes reformistas como rupturistas en la Iglesia, a través de un viaje de dos sentidos: de las transformaciones sociales y eclesiales a la crisis de la vida clerical y religiosa, y viceversa. Y concluyo - a partir de la información incorporada y de los materiales estudiadosrefutando la idea inicial con la que iniciaba el texto, rechazando el inevitable binomio por el cual la secularización y la religiosidad constituyen fenómenos opuestos o de un único sentido desde la secularización hacia la religiosidad. Frente a esta concepción, la aproximación histórica nos revela una imagen más matizada, en la que se interrelacionan y entrelazan los distintos vectores. Máxime en el periodo de los sesenta, en el que se inició una nueva oleada de secularización desde una base social en la que la presencia de la religiosidad católica y de sus custodios, sacerdotes y religiosos, era indudable. Desde esta perspectiva, la crisis del clero y de los religiosos se nos revela de modo particular como reflejo de las transformaciones sociohistóricas que se estaban experimentando, pero también como factor de las mismas hacia la configuración de lo que desde la sociología se ha denominado como "segunda oleada de secularización» (Pérez-Agote 2012).

Reflejo, porque la crisis del sector de sacerdotes y religiosos sintetizó de manera particularmente intensa las crecientes problematizaciones que las transformaciones sociales implicaban para los modos en los que la religión había estado presente, y concretamente para la reproducción de la figura del clero y de los religiosos. Los dilemas generacionales y demográficos, la interpretación de la invalidez de las viejas estructuras ante la novedad de una sociedad modernizada y una Iglesia posconciliar, o la idea de convulsión total de lo antiguo por lo nuevo revelaban que la cristiandad hacía colapso y con ella «toda la aneja configuración del sacerdote según dichos moldes» (Andreu et al. 1971, 199).

Pero también factor, porque la rapidez que tomó el cambio en la propia estructura de la Iglesia actuó como un acelerador del propio proceso de transformación sociorreligiosa. Por un lado, en las áreas más «incontaminadas» aún por la expansión de la sociedad de consumo, los sacerdotes y religiosos actuaron como líderes de transformación incluso antes de la llegada de la televisión, aparato que sintetizaba la novedad del periodo. Por otro lado, en los espacios ya inmersos en procesos de transformación social durante los sesenta, los sacerdotes y religiosos más desidentificados tanto con su rol como con la Iglesia contribuyeron a la erosión de la tradición religiosa. La opción por una fe desligada de la herencia del pasado y radicada en la conciencia, que en unos casos dio lugar a un cristianismo "más auténtico" y libre, en otros fue sucedido por una desestructuración mayor de la religiosidad católica, síntoma principal de la segunda oleada de la secularización y muestra de la potencial influencia de la crisis del clero y los religiosos en la aceleración de la transformación sociorreligiosa en el caso histórico de España. 
En definitiva, el análisis histórico de la secularización nos revela su composición compleja, en el que los cambios emergen de manera multicausal y rizomática (Skornicki 2015, 91; McLeod 2007, 15), múltiples cambios, procedentes de diferentes espacios sociales, que interactuaron entre ellos y fraguaron diferentes rupturas con los modos en los que la religión había estado presente hasta la década de los sesenta.

Esta constatación nos conduce a afirmar que la secularización interna de la iglesia, especialmente en sociedades como la española, en la que la presencia del clero y de los religiosos era fundamental, no conformó una mera consecuencia o una línea secundaria, supeditada a otras explicaciones sobre la secularización. Fue también parte esencial y constituyente del mismo proceso de secularización. $\mathrm{Y}, \mathrm{a}$ su vez, apunta a la necesidad de una mayor profundización histórica sobre los múltiples rostros del proceso de secularización. Lejos de los binomios irresolubles con los que comenzábamos, la aproximación histórica a la secularización nos revela una historia menos lineal y más compleja, en la que los agentes religiosos no son simples receptores pasivos del cambio, sino también actores con voz propia en la transformación del tejido social.

\section{FUENTES}

$A B C$. 1966. "Los cambios en el traje talar de los sacerdotes». ABC (Madrid), 8 de junio.

ABC. 1969. «El número de sacerdotes que en los últimos seis años han pedido la secularización». $A B C$ (Sevilla), 4 de julio.

ABC. 1970. «Se crea un departamento para ayudar a los sacerdotes y religiosos secularizados». $A B C$ (Sevilla), 7 de junio.

Anuario de la Compañía de Jesús. 1960. sl.: se.

Anuario de la Compañía de Jesús. 1965. sl.: se.

Anuario de la Compañía de Jesús. 1970. sl.: se.

Comisión Episcopal de Pastoral. 1975. Juventud 1975. Informe. Madrid: Secretariado nacional de catequesis.

Confederación Española de Religiosos. 1966a. Guía de las comunidades religiosas en España. I Comunidades Masculinas. Madrid: Confederación Española de Religiosos.

Confederación Española de Religiosos. 1966b. Guía de las comunidades religiosas en España. II Comunidades Femeninas. Madrid: Confederación Española de Religiosos.

Confederación Española de Religiosos. 1972. Guía de las comunidades religiosas masculinas de España. Madrid: CONFER.

Fundación FOESSA. 1966. Informe sociológico sobre la situación social de España. Madrid: Fundación FOESSA.

Gálvez, Antonio. 1971. "El siete», carta al director. ABC (Sevilla), 12 de mayo.

Moreno Nieto, Luis. 1971. «El cardenal primado analiza en una pastoral el problema de la escasez de vocaciones sacerdotales». $A B C$ (Madrid), 24 de abril.

Oficina General de Información y Estadística de la Iglesia. 1973. Guía de la Iglesia en España. Madrid: Secretariado del Episcopado Español-Oficina General de Información y Estadística de la Iglesia en España.

Ordóñez Márquez, Juan. 1970. «Doctora tiene la Iglesia». ABC (Sevilla), 26 de septiembre.

\section{Biblografía}

Abella, Rafael. 1985. La vida cotidiana en España bajo el régimen de Franco. Barcelona: Argos Vergara.

Acebal, Luis. 1969. «Sacralización y desacralización en la España actual». Iglesia viva 21: 169-183.
Alcalá, Manuel. 1976. «(XIII) Panorámica moral: lenta reacción renovadora». Ecclesia 1780: 14-17.

Andrés-Gallego, José y Antón M. Pazos. 1999. La Iglesia en la España contemporánea, vol. 2. Madrid: Encuentro.

Andreu, Agustín, J. Bengoa, Antonio Duato, José Francisco Fontecha, Enrique Freijo, Luis Maldonado, Casimir Martí, Joaquín Perea, Ramón Prat y José María Rovira. 1971. «Reflexiones teológicas sobre los datos sociológicos de la encuesta nacional del clero». Iglesia Viva 33: 199-244.

Aradillas, Antonio. 1977. Yo acuso. Madrid: Sedmay.

Asamblea Conjunta Obispos-Sacerdotes. 1971. Asamblea Conjunta Obispos-Sacerdotes. Historia de la Asamblea. Discursos. Texto íntegro de todas las ponencias. Proposiciones. Conclusiones. Apéndices. Madrid: Biblioteca de Autores Cristianos.

Béraud, Céline. 2007. Prêtres, diacres, laïcs. Révolution silencieuse dans le catholicisme français. Paris: Presses Universitaires de France.

Berzal de la Rosa, Enrique. 2007. Sotanas rebeldes: contribución cristiana a la Transición democrática. Valladolid: Diputación Provincial de Valladolid.

Botti, Alfonso. 2008. Cielo y dinero. El nacionalcatolicismo en España 1881-1975. Madrid: Alianza Editorial.

Botti, Alfonso y Nieves Montesinos. 1998. «Anticlericalismo y laicidad en la Posguerra, la Transición y la Democracia (1939-1995)». En El anticlericalismo español contemporáneo, edición de Emilio La Parra y Manuel Suárez, 303-370. Madrid: Biblioteca Nueva.

Brown, Callum G. 2009. The Death of Christian Britain. Understanding Secularization 1800-2000. Oxford: Routledge.

Cardenal, Juan Bautista. 1972. El problema más urgente de la Iglesia. Madrid: Apostolado de la Prensa.

Castro, Ángel de y Margarita Serrano. 1977. La gran desbandada (curas secularizados). Madrid: Editorial Cuadernos para el Diálogo.

Centeno García, José, Luis Díez Maestro y Julio Pérez Pinillos. 2009. Curas obreros. Cuarenta y cinco años de testimonio. Barcelona: Herder.

Christian, William A. Jr. 1978. Religiosidad popular. Estudio antropológico en un valle español. Madrid: Tecnos.

Comas Arnau, Domingo. 2006. "La evolución del pluralismo religioso en España». Letra internacional 90: 39-54.

Cuchet, Guillaume. 2018. Comment notre monde a cessé d'être chrétien. Anatomie d'un effondrement. París: Éditions du Seuil.

Cueva, Julio de la. 2018. "La secularización tranquila: procesos de secularización bajo el franquismo (1960-1975)». En Encrucijadas del cambio religioso en España. Religión, cristianismo e islam, edición de Julio de la Cueva, Miguel Hernando de Larramendi y Ana I. Planet, 31-52. Granada: Comares.

Cueva, Julio de la y Feliciano Montero, eds. 2007. La secularización conflictiva en España (1898-1931). Madrid: Biblioteca Nueva.

De Certeau, Michael y Jean-Marie Domenach. 1974. Le christianisme éclaté. Paris: Editions du Seuil.

De Riquer, Borja. La dictadura de Franco, vol. 9. Madrid: Crítica-Marcial Pons.

Domínguez Rojas, Jesús. 2001. «La Iglesia española en cifras. Análisis de los datos estadísticos (1960-1980)». Anuario de Historia de la Iglesia 10: 31-55. https://revistas.unav.edu/index.php/anuario-dehistoria-iglesia/article/view/24387

Duocastella, Rogeli. 1965. "Géographie De La Pratique Religieuse En Espagne». Social Compass 12 (3): 253-302. https://doi. org/10.1177/003776866501200303

Duocastella, Rogeli. 1971a. «El sacerdote, punto clave de la Iglesia institucional». En La sociedad española, el rol del sacerdote y la autoridad de la Iglesia, coordinado por J. Cardus, R. Duocastella, J. Estruch, F. Houtart, J. Giménez, C. Marti, M. Reixach, J.M. Rovira Belloso, J.I. Ruiz de Olabuénaga, 123-161. Barcelona: Publicaciones ISPA.

Duocastella, Rogeli, 1971b. «La percepción del rol del sacerdote en la sociedad española». En La sociedad española, el rol del sacerdote y la autoridad de la Iglesia, coordinado por J. Cardus, R. Duocastella, 
J. Estruch, F. Houtart, J. Giménez, C. Martí, M. Reixach, J.M. Rovira Belloso, J.I. Ruiz Olabuénaga, 3-76. Barcelona: Publicaciones ISPA.

Estrada, Juan Antonio. 2008. Religiosos en una sociedad secularizada. Por un cambio de modelo. Madrid: Trotta.

Fierro, Alfredo. 1968. «¿Qué hay del cura?». Iglesia Viva 16: 315-337.

González, Nazario. 1962. "Sacerdocio y profesiones laicales». Razón y Fe CLXV: 137-150.

González de Cardedal, Olegario. 1967. ¿Crisis de seminarios o crisis de sacerdotes? Madrid: Marova.

González de Cardedal, Olegario. 1985. España por pensar. Salamanca: Publicaciones Universidad Pontificia de Salamanca.

González de Cardedal, Olegario. 2010. La teología en España (19592009). Memoria y prospectiva. Madrid: Editorial Encuentro.

Gorski, Philip S. 2003. "Historicizing the Secularization Debate: An Agenda for Research». En Handbook of the Sociology of Religion, edición de Michele Dillon, 110-122. Nueva York: Cambridge University Press.

Gracia, Jordi y Miguel Ángel Ruiz Carnicer. 2004. La España de Franco (1939-1975). Madrid: Síntesis.

Hermet, Guy. 1985. Los católicos en la España franquista. I. Los actores del Juego Político. Traducido por Carmen-Ana Hernández-Rubio. Madrid: Centro de Investigaciones Sociológicas.

ISPA. 1971. La formación religiosa en los colegios de la Iglesia. Barcelona: Instituto de Sociología y Pastoral Aplicadas.

Koselleck, Reinhart. 2003. Aceleración, prognosis y secularización. Valencia: Pre-textos.

Laboa, Juan María. 2017. Pablo VI, España y El Concilio Vaticano II. Madrid: PPC.

Marías, Julián. 1984. "La actitud religiosa de siete generaciones españolas». En Iglesia, Estado y Sociedad en España. 1930-1982, edición de Joaquín Ruiz-Giménez, 325-332. Barcelona: Argos Vergara.

Martín de Santa Olalla, Pablo y José Francisco Serrano Oceja. 2016 50 años de la Conferencia Episcopal Española. Madrid: Encuentro.

Martín Descalzo, José Luis. 1976. «La Iglesia española entre ayer y mañana». Razón y fe 940: 449-460.

McLeod, Hugh. 2007. The Religious Crisis of the 1960s. Oxford: Oxford University Press.

Mérida, María. 1982. Entrevista con la Iglesia. Barcelona: Planeta.

Miret Magdalena, Enrique. 1968. Panorama religioso. Madrid: Guadiana de Publicaciones.

Montero, Feliciano. 2009. La Iglesia: de la colaboración a la disidencia (1956-1975). La oposición durante el franquismo. Madrid: Encuentro.
Pelletier, Denis. 2002. La crise catholique. Religion, société, politique. París: Payot.

Pérez-Agote, Alfonso. 2010. "Los límites de la secularización: hacia una versión analítica de la teoría». En Sagrado/Profano. Nuevos desafíos al proyecto de la modernidad, edición de Josetxo Beriain e Ignacio Sánchez de la Yncera, 291-322. Madrid: Centro de Investigaciones Sociológicas.

Pérez-Agote, Alfonso. 2012. Cambio religioso en España: los avatares de la secularización (colección monografías, 276). Madrid: Centro de Investigaciones Sociológicas.

Pintos, Juan-Luis. 1968. «Actitud religiosa de los universitarios». Razón y fe 843: 387-398.

Raguer, Hilari. 2006. Réquiem por la Cristiandad. El Concilio Vaticano II y su impacto en España. Barcelona: Península.

Requena, Miguel. 1994. "Juventud y religión en España». En Historia de los cambios de mentalidades de los Jóvenes entre 1960-1990, dirigido por Olivia Velarde Hermida, Antonio Alaminos, Francisco Bernete García, Mauricio Martín Escudero, Antonio Muñoz Carrión, Miguel Requena y Díez de Revenga y Manuel Martín Serrano, 77-97. Madrid: Instituto de la Juventud.

Richards, Michael. 2013. Historias para después de una guerra. Memoria, política y cambio social en España desde 1936. Barcelona: Pasado y presente.

Sans Vila, Jorge y Ramón María. 1965. Por qué me hice sacerdote. Salamanca: Sígueme.

Sebastián, Fernando. 1970. «Reflexiones teológicas a propósito de una encuesta a los seminaristas españoles». Iglesia Viva 28-29: 419445.

Skornicki, Arnault. 2015. "Los orígenes teológico-políticos del biopoder. Pastoral y genealogía del Estado». Traducido por Salvador Cayuela Sánchez. Sociología Histórica 5: 67-91

Sopeña, Federico. 1970. Defensa de una generación. Madrid: Taurus Ediciones.

Taylor, Charles. 2015. La Era Secular. Tomo II. Traducido por Ricardo Pérez. Barcelona: Gedisa.

Taylor, Mark C. 2011. Después de Dios. La religión y las redes de la ciencia, el arte, las finanzas y la política. Madrid: Siruela.

Urbina, Fernando. 1981. "Hacia un replanteamiento actual de la problemática del ministerio sacerdotal en la Iglesia Católica». Iglesia Viva 91-92: 7-28.

Vázquez, Alfredo. 1976. "La situación religiosa en España». En Estudios sociológicos sobre la situación social de España 1975, 529-704. Madrid: Euramérica.

Vázquez, Jesús María, Félix Medín y Luis Méndez. 1973. La Iglesia española contemporánea. Madrid: Editora Nacional. 
